\title{
“Trabalhar É Manter-Se Vivo": Envelhecimento e Sentido do Trabalho para Docentes do Ensino Superior
}

\section{"Work Is Staying Alive": Aging and Sense of Work for Teachers of Higher Education}

\author{
Rejane Prevot Nascimento \\ Doutora em Engenharia de Produção pela UFRJ \\ Professora e Coordenadora do Mestrado Acadêmico em Administração da Universidade do \\ Grande Rio \\ E-mail: rejaneprevot@uol.com.br \\ Débora Vargas Ferreira Costa \\ Doutoranda em Administração da Universidade do Grande Rio \\ Professora da Universidade Federal de Juiz de Fora \\ E-mail: deboravargas82@gmail.com \\ Maria Nair Rodrigues Salvá \\ Mestre em Administração pela Universidade do Grande Rio \\ E-mail: mnairrodrigues@yahoo.com.br \\ Renan Gomes de Moura \\ Mestrando em Administração da Universidade do Grande Rio \\ E-mail: renangmoura@gmail.com \\ Lutumba António Sebastião Simão \\ Mestrando em Administração da Universidade do Grande Rio \\ E-mail: lasstorra@msn.com
}

\begin{abstract}
Resumo
Diante das mudanças no perfil demográfico da população brasileira, com a elevação no número de idosos, o tema envelhecimento populacional tem sido bastante estudado por áreas das Ciências Humanas e da Saúde. No entanto, ainda encontra-se uma grande lacuna no que diz respeito a esses estudos na área de Administração. $O$ objetivo do presente artigo é compreender o sentido do trabalho para o professor idoso de ensino superior. Com a finalidade de dar suporte ao estudo, são resgatadas teorias acerca da centralidade do trabalho, envelhecimento e sentido do trabalho, aposentadoria e sobre a docência. A pesquisa é de natureza qualitativa e os dados foram coletados por meio de pesquisa de campo. O corpus de entrevistados foi composto por 16 docentes. As entrevistas realizadas em profundidadeforamanalisadas por meio do método da análise de conteúdo. Pôde-se perceber que o trabalho para os sujeitos entrevistados é algo de extrema importância, que a aposentadoria é indesejada e temida e que os professores sentem preconceito no trabalho por conta de sua idade. Nas relações de gênero existentes no ambiente profissional, evidenciou-se a existência de preconceito não declarado por parte dos homens frente ao trabalho feminino.
\end{abstract}

Palavras chave: Envelhecimento; Sentido do Trabalho; Docente do Ensino Superior. Artigo apresentado no VI Congresso Nacional de Administração e Contabilidade - AdCont 2015, RJ. Artigo submetido em fevereiro de 2016 e aceito em julho pela editora Fernanda Sauerbronn, após processo de double blind review. 


\begin{abstract}
In the face of changes in the demographic profile of Brazilian population with the increase in the number of elderly people, the subject population aging has been extensively studied by areas of Human and Health Sciences. There is still a big gap regarding to these studies in the area of administration. The goal of this article is to understand the meaning of work for elderly professor of higher education. In order to support the study, theories are redeemed about the centrality of work, aging and meaning of work, retirement and on teaching. The research is qualitative and data were collected through field research. The corpus of interviewees was composed of 16 teachers. The interviews were analyzed in depth by the method of content analysis. It could be perceived that the work for the interviewees is something very important, that retirement is unwanted and feared and that teachers feel prejudice at work because of their age. In existing gender relations in the workplace, showed the existence of prejudice is not declared by the men against the women work.
\end{abstract}

Keywords: Aging; Meaning of Work; Professor of Higher Education.

\title{
1 Introdução
}

De acordo com o IBGE (2013), os brasileiros estão vivendo cada vez mais e com mais saúde. Segundo dados do mesmo instituto, a expectativa de vida no Brasil que em 1960 era próxima de 49 anos de idade, chegou a 62 anos e meio em 1980 e hoje está em mais de 74 anos, um acréscimo superior a $50 \%$.

Carvalho (2009) aponta que há uma projeção de que em 2020 o percentual de idosos incluídos entre a População Economicamente Ativa será de 13\% (em 1998 este percentual era de 9\%). Apesar desta expectativa, ainda há uma barreira nas empresas para a contratação de pessoas idosas, além do despreparo dos departamentos de Gestão de Pessoas para lidar com as questões associadas ao trabalho na velhice. Este fato pode ser uma das razões para o alto percentual de idosos inseridos no mercado informal (50\% daqueles que possuem alguma ocupação), conforme demonstra Carvalho (2009), a partir de dados da PNAD.

O crescimento progressivo desta parcela da população tem trazido desafios que apontam o envelhecer e suas consequências como um dos temas de grande discussão, indicando uma necessidade de compreender melhor o novo conceito de velhice e suas implicações (FONTOURA; PICCININI, 2012). Para Braga et al. (2008), o mundo ainda não assimilou satisfatoriamente esta situação e as necessidades advindas da desatenção às faixas etárias mais altas. Para isso é necessário que sejam reconhecidos e estudados prioritariamente. Além disso, a sociedade, com o auxílio destas novas políticas, com desempenho de novas ações programas a serem postas em prática, poderão vivenciar a presença destes idosos junto à sociedade ativa, repensando e promovendo a transformação cultural do ponto de vista em relação a idoso e os preconceitos e convenções que os cercam.

O efeito demográfico crescente, aliado à tendência de mantermos os números de taxas de atividade de pessoas em processo de envelhecimento, resulta entre outros fatores, no crescimento da participação da população acima de 60 anos no efetivo de trabalhadores. Sendo assim, abordar esta tendência é imprescindível, na medida em que se o país envelhece em virtude da melhoria da qualidade de vida, tem-se uma melhora da capacidade laboral e, como efeito, o envelhecimento da força de trabalho (CAMARANO, 2001). 
Entretanto, fazendo uma pesquisa preliminar sobre a temática do envelhecimento no campo das Ciências Sociais Aplicadas, em particular na área de Administração, observa-se que a área não está acompanhando, em termos de pesquisa e produção científica, o conjunto de transformações decorrentes do envelhecimento populacional e, mais especificamente, do crescente processo de inserção dos idosos nas organizações. Um breve levantamento no Banco de Teses da CAPES, por exemplo, nos mostra que a temática do envelhecimento é objeto de estudos majoritariamente na área de saúde, seguida pela psicologia, serviço social, ciências sociais e outras disciplinas.

Neste contexto, face à carência de estudos que abordem o envelhecimento sob o enfoque do trabalho e do mercado de trabalho, principalmente na área de Administração, em particular na subárea de Gestão de Pessoas e considerando-se a necessidade de adequação das políticas públicas de trabalho e emprego e das políticas de gestão das organizações ao processo de envelhecimento da força de trabalho o presente projeto procura responder a seguinte pergunta de pesquisa: Qual o sentido do trabalho para o professor idoso de ensino superior?

Diante do exposto, o objetivo do presente artigo é compreender o sentido do trabalho para o professor idoso de ensino superior. O artigo está estruturado em cinco seções, contando com esta introdução. A próxima está dedicada a apresentar o que foi levantado na revisão da literatura. Em seguida, são explicitados os procedimentos metodológicos adotados. A quarta seção expões e analisa os dados levantados na pesquisa. Por fim, são apresentadas as considerações finais do estudo.

\section{Referencial Teórico}

De acordo com o Instituto Brasileiro de Geografia e Estatística (IBGE), no Censo de 2010, o Brasil caminha para tornar-se um País com população de maioria idosa em 2030. Seguindo esta projeção, o percentual do grupo de idosos com idade de 60 anos ou mais, será maior que o grupo de crianças com até 14 anos. Este contexto tem implicação diretamente sobre vários aspectos da sociedade, inclusive sobre o mercado de trabalho, pois o indivíduo que tem maior expectativa de vida tende a permanecer mais tempo trabalhando, o que denota o envelhecimento da força de trabalho, tendência que continuará ocorrendo, de acordo com os pesquisadores.

\subsection{A Centralidade do Trabalho}

A significativa mudança no modo de funcionamento do capitalismo, observada a partir da década de 1970, promoveu as transformações ocorridas no campo da tecnologia, da economia, da cultura e do trabalho, acentuando as transformações do sistema de acumulação flexível e dos processos que o mundo do trabalho vem sofrendo no âmbito da produção, com impactos consideráveis para as relações do indivíduo e da sociedade (HARVEY, 1989).

O elemento central deste cenário neoliberal era a maximização da concorrência e da competitividade do mercado em prol do crescimento e do desenvolvimento, promovendo, dessa forma, a flexibilidade do mercado de trabalho, "o que passou a significar uma agenda para a transferência de riscos e insegurança para os trabalhadores e suas famílias" (STANDING, 2013, p. 15).

Essas consequências no interior do mundo do trabalho evidenciam que, sob o capitalismo, não se constata o fim do trabalho como medida de valor, mas uma mudança qualitativa, dada, por um lado, pelo peso crescente da sua dimensão mais 
qualificada do trabalho multifuncional, do operário apto a operar com máquinas informatizadas, da objetivação de atividades cerebrais. (ANTUNES, 2008, p. 199).

A acumulação flexível, diferentemente do que ocorria no taylorismo/fordismo, onde as competências eram desenvolvidas com foco em ocupações previamente definidas e relativamente estáveis, a integração produtiva se alimenta do consumo flexível de competências diferenciadas, que se articulam ao longo das cadeias produtivas. Estas combinações não seguem modelos preestabelecidos, sendo definidas e redefinidas segundo as estratégias de contratação e subcontratação que são mobilizadas, tendo em vista atender, de forma competitiva, às necessidades do mercado (KUENZER, 2008, p. 493).

Afirma Gorz (2007), que a crise funcional do trabalho promoveu o fim do humanismo no trabalho, devido à racionalização econômica proposta pela informatização e pela robotização, gerando tempo de trabalho disponível para a geração de riquezas. Ressalta o autor que:

Há a necessidade de se modernizar os pressupostos sobre os quais está fundada a modernidade. A atual crise não é uma crise da razão, mas a crise dos motivos irracionais [...] quase religiosos, sobre os quais se edificou essa racionalização seletiva e particular que é o industrialismo, portador de uma concepção do universo e de uma visão do futuro doravante insustentáveis. (GORZ, 2007, p. 130).

Dejours (2012) salienta a iminência do fim do trabalho, através da existência de um poder imaginário social contemporâneo que, encantado pela economia virtual, celebra um mundo reduzido a ser apenas coisa de gestores. Sob este aspecto, Gaulejac (2007, p. 29) observa que "a gestão não é um mal em si. É legítimo organizar o mundo, racionalizar a produção, preocupar-se com a rentabilidade". No entanto, a gestão capitalista obedece à lógica da obsolescência, da cultura do alto desempenho, colocando o mundo sob pressão e trazendo efeitos deletérios para o indivíduo; enquanto o estresse, o esgotamento profissional e o sofrimento no trabalho se banalizam.

Devido às metamorfoses ocorridas no processo de produção de capital é que a perda ou a retração da centralidade do trabalho é tema recorrente. Segundo Bauman (2004, p. 158), o papel principal atribuído ao trabalho, nos tempos modernos, é o de colocar a espécie humana no comando de seu próprio destino, na qualidade de "condição natural do ser humano", em busca de afirmação no espaço social, através de um esforço coletivo (BAUMAN, 2004, p. 158). Desta forma, no próximo item será trabalhado em complemento ao tema, o sentido do trabalho para o idoso, na qualidade de fator estruturante do ser social no mundo contemporâneo.

\subsection{O Envelhecimento e o Sentido do Trabalho para o Idoso}

Definir sentido do trabalho é, senão, uma das tarefas mais difíceis, pois "Os sentidos do trabalho estão, historicamente, vinculados às condições materiais da sociedade. Assim, as mutações civilizatórias que permeiam a sociedade em geral também se fazem presente no contexto das organizações de trabalho, alterando e propiciando novas produções simbólicas" (ARAÚJO, SACHUK, 2007, p.63). Ressalta-se que o trabalho ocupa um papel importante na vida dos indivíduos, pois "o trabalho é central na vida das pessoas, engajando toda a subjetividade do trabalhador: é e continuará central em face daconstrução da identidade e da 
saúde, da realização pessoal, da formação das relações entre homens e mulheres, da evolução da consciência da cultura" (VIANA, MACHADO, 2009, p. 1).

Para compreender o significado de sentido do trabalho, faz-se necessário entender o conceito da palavra "sentido", tendo em vista que a mesma pode variar seu significado de acordo com o contexto e a visada ao qual é empregada. Neste trabalho, a palavra sentido será conceituada de acordo com a abordagem construcionista. Lima et al. (2013), relatam que a palavra sentido é considerada pelo construcionismo como uma construção social resultante da relação do indivíduo, de forma coletiva e interativa com situações e fenômenos que os cercam. Já Vygotsky (1991), conceitua sentido como o somatório de todos os eventos psicológicos evocados no nosso consciente e expresso em palavras sendo assim possui uma formação dinâmica, complexa e variável. Partindo dessa premissa, é possível relatar que o sentido que cada indivíduo emprega a algo é subjetivo e variável, pois tal ato está relacionado às vivencias de cada sujeito, que podem ser de forma coletiva ou individual.

Referindo-se ao sentido do trabalho, Antunes (2009), relata que os indivíduos só conseguem dar sentido à vida fora do trabalho, a partir do momento que se tem uma vida dotada de sentido dentro do trabalho. Nota-se que o trabalho está cheio de sentido para a vida dos indivíduos, não ocupando apenas o papel de provedor de recursos financeiros. No que se tange ao conceito de sentido do trabalho propriamente dito ressalta-se que o mesmo, de uma maneira geral, pode ser divido em duas fases históricas, o sentido do trabalho moderno e o pós-moderno. Bendassolli (2009) relata que o sentido do trabalho na Modernidade era expresso através de meta-narrativas sociais que faziam com que as narrativas dos sujeitos dependessem da mesma; já na Pós-modernidade o sentido do trabalho abandonou um conceito singular para se tornar plural, ou seja, passou a existir diversos sentidos do trabalho, dificultando assim em criar uma relação direta com a construção da identidade dos sujeitos, "é como se o trabalho deixasse de ser a única objetivação possível para o ser, sua única - ou mais privilegiada - forma de revelação.” (BENDASSOLLI, 2007, p. 22).

Referindo-se ao sentido do trabalho para os sujeitos Pagèset al. (2006), relata que o sentido atribuído ao trabalho está relacionado à influência da ideologia que os orienta ideologias dominantes - que são decorrentes de vivencias cotidianas do indivíduo como herança cultural, fatos históricos e qualquer outro fato ao qual o indivíduo se submete. Completando a ideia exposta por Pagèset al (2006), Dourado et al. (2009, p. 353), relatam que "O sentido que os indivíduos dão ao trabalho ganha importância distinta de acordo com a lógica que orienta as principais perspectivas teológicas”. Na Idade Média, por exemplo, o trabalho era valorizado de acordo em que favorecia a limpeza da mente, a fim de que não permitisse ao homem ter pensamentos pecaminosos e afastando os indivíduos da preguiça (CARMO, 1992). Posteriormente com a Reforma Protestante há a incorporação da vocação para o trabalho, tornando-se motivo de orgulho e sacrifício, pois Deus abençoava aqueles que trabalhavam, pois era considerado como a própria finalidade da vida, sendo assim a ausência da vontade de trabalhar era sinônimo da ausência da graça divina (WEBER, 2002).

E o que dizer sobre o sentido do trabalho para o Idoso? Apesar de o envelhecimento biológico ter ligação com idade dos indivíduos, devem-se considerar todas as variáveis relacionadas ao envelhecer, não nos restringindo apenas a idade. As implicações da velhice podem estar atreladas ao contexto, à cultura, à época vivida, e também às histórias de vida que variam de indivíduo para indivíduo, não podendo assim traçar um determinante preciso sobre este conceito. Logo, não se deve pensar no envelhecimento com uma experiência homogênea (DEBERT, 1997).

Destacando a diversidade deste universo chamado envelhecimento, Engel (2012) cita que há também a existência de diferentes grupos dentro do montante denominado população Costa, D. V. F.; Moura, R. G.; Nascimento, R. P.; Salvá, M. N. R.; Simão, L. A. S. 
idosa, com utilização de nomenclaturas como terceira idade, jovens idosos, quarta idade, envelhecidos funcionais, entre outros, o que explicita que a população idosa não cresce apenas em quantidade, mas também em qualidade. Com o aumento significativo desta parcela da população e a existência de variações de qualidade deste envelhecimento, o tema oferece um contexto diferenciado aos estudiosos. As discussões deslocam-se de uma fase onde a sobrevida das pessoas que envelhecem era consideravelmente menor e avaliada como a pior fase da vida passando para um momento onde há possibilidades de mudanças acerca da vida do idoso, onde este cidadão pode não ser interpretado como um "problema" e sim como sujeito capaz de produzir, que têm direitos e deveres e, principalmente, poder de decisão sobre sua vida e seu futuro (CARVALHO, 2009).

Oliveira e Scortegagna (2009) destacam que esta participação, atualmente, vem sendo possibilitada pela mudança acerca de variáveis em relação ao trabalho, tais como a criatividade e o crescimento intelectual, que hoje não estão mais atrelados diretamente à deterioração em virtude da idade, mas sim como características individuais dos seres humanos. Desta forma, as atividades e a participação dos indivíduos mais velhos tornam-se mais uma questão de adequação funcional, do que meramente um rótulo de idade avançada.

Souza (2010) comenta que, de maneira geral, o sujeito apenas percebe o próprio envelhecimento através da imagem corporal do outro. Sendo assim, um sujeito que envelhece de maneira natural e saudável, atravessa apenas uma fase de adaptação, como uma nova fase do desenvolvimento, uma espécie de equilíbrio biológico e não percebe a 'velhice'. Neste sentido, as sociedades passaram a se deparar com um grande número de idosos com perfil bastante diferente de alguns anos atrás. São pessoas mais ativas, saudáveis e principalmente ainda produtivas.

Coutrim (2006), afirma que as pesquisas atuais apontam que grande parte dos idosos hoje tem capacidade de trabalhar e realizam, efetivamente, estas atividades. Wajnman, Oliveira e Oliveira (2004) complementa que os idosos mais disponíveis para o trabalho são dependentes do rendimento da atividade econômica, são homens, chefes de família, negros, os de menor renda familiar, os aposentados e trabalhadores de ocupações manuais. Contudo, os que têm maior probabilidade de se manter ocupados com idades mais avançadas são os de nível de escolaridade maior.

A baixa escolaridade, o alto nível de exigência e a qualificação criteriosa também contribuem para o baixo número de pessoas mais velhas inseridas no mercado de trabalho formal. De acordo com Ximenes (2009), os idosos acabam sendo inseridos em sua grande maioria no mercado do trabalho informal, ou subemprego. Independente do setor, as pessoas mais velhas que procuram um novo emprego, ganham em qualidade de vida, pois além de ganharem uma renda extra, previnem a ociosidade e aumentam a autoestima por sentirem-se ativas e úteis.

As diferenciações das concepções do trabalho também colaboram para a mudança deste contexto. Antigamente, a concepção de trabalhador estava diretamente relacionada à força física e seria cruel com o idoso exercer uma atividade que o traria ainda mais desgaste físico e psicológico, levando a uma ideia de injustiça e desmerecimento. Assim, a saída do mercado de trabalho, a aposentadoria, significava um prêmio pelos anos de sofrimento. Contudo, a atividade laboral hoje tem um entendimento muito mais abrangente, embora ainda distante do ideal (POLETINNI, 2010). Esta nova maneira de significar o labor, contribui para a inserção do idoso no mercado de trabalho, uma vez que gradativamente as empresas vêm valorizando o potencial do conhecimento do trabalhador e a experiência profissional adquirida 
ao longo dos anos, o que concorda com a ideia de Oliveira e Scortegagna (2009), sobre a adequação funcional possibilitar o emprego destes trabalhadores.

Polettini (2010) comenta ainda que o idoso que trabalha é considerado executor, possui um papel ativo, é produtivo, provedor, gerador de bens e para tal precisa atender a determinadas exigências físicas, psicológicas e sociais, assumindo responsabilidade e cumprimento de carga horária definida pelo empregador. Em contrapartida, o passivo está ligado à ausência de produtividade, alimentada por benefícios, de pouca competência física, atividade lenta e sem exigências de obrigações. Esta polaridade de conceitos contribui para um entendimento deturpado da realidade, pois é bem verdade que fisiologicamente, as atividades que exigem rapidez e força, de maneira geral são mais difíceis para pessoas idosas, contudo há funções que podem ser desempenhadas com competência, ou mesmo conveniências, opinião também já exposta por Giaqueto e Soares (2010).

É no trabalho, portanto, que os homens se constroem como seres diferentes da natureza. É pelo trabalho que eles não apenas produzem os bens necessários a sua sobrevivência, como ainda produzem, ao mesmo tempo, as novas necessidades e possibilidades, e as novas habilidades e conhecimentos dos indivíduos, que possibilitarão à história caminhar em direção à construção de sociedades cada vez mais complexas (GIAQUETO E SOARES, 2010).

Para Carvalho (2009), o trabalho tem dimensões significativas na vida do ser humano, como manter financeiramente o orçamento da família, garantir sua liberdade de autonomia, o exercício mental, identificação perante a sociedade, exercício da cidadania, pois trabalhando sente-se ativo e participante da sociedade, além de preservar suas relações sociais.

Sikotae Bretas (2012) menciona, em pesquisa realizada com vendedores ambulantes já idosos, que nas narrativas encontradas percebe-se a importância do trabalho como fonte de renda complementar e propiciadora de planos futuros, mas, sobretudo, o sentimento de utilidade e independência, que desmitifica a "velhice". Ainda de acordo com o autor, o trabalho é uma maneira de realização do indivíduo, de sentir-se útil e de pertencer à sociedade, além de relatarem que gostam do que fazem.

Coutrim (2006) ressalta a pesquisa do autor anterior, quando cita que o idoso que trabalha, independente da sua situação previdenciária adota uma postura diferente da de um cidadão aposentado, pois possui poder de decisão no domicílio. Transparece orgulho do trabalho e destacam o fato de serem chefes da família, ou seja, de não serem excluídos das decisões familiares e tornam-se referência para os filhos e netos que moram na mesma casa. A identidade instalada é a de trabalhador, provedor inserido no contexto familiar e social, estando assim muito distantes da segregação e com certa liberdade financeira.

\subsection{A Aposentadoria e os Aspectos Econômico e Social}

De acordo com Carvalho (2009), quando o Sistema Previdenciário do país foi planejado, em 1940, a expectativa de vida do brasileiro era de 50 anos. Naquele cenário os gastos eram baixos para o contingente de cidadãos que gozariam do benefício da aposentadoria até o final da vida. Hoje a despesa para os cofres públicos é alta, uma vez que o número de cidadãos com idade avançada é alto e o Estado se vê diante da dívida (dívida esta que muitas vezes não consegue dar manutenção a vida digna do aposentado), e ainda perde o trabalhador como contribuinte, por sair do mercado de trabalho. Alguns países desenvolvidos estão reformulando seus sistemas previdenciários no sentido de preterir a aposentadoria, já que hoje a realidade é outra. 
Não se pode negar que a aposentadoria é uma conquista dos direitos trabalhistas, e tem como objetivo melhorar essa qualidade de vida após o período de trabalho em que contribuiu para sociedade e deve oferecer segurança monetária ao trabalhador. Contudo, vemos que o termo aposentado ainda traz consigo certa ideia de degradação da pessoa, tanto de seus aspectos mentais quanto, se não principalmente, do ponto de vista social. (Carvalho, 2009).

A Previdência Social é o seguro social para a pessoa que contribui. É uma instituição pública que tem como objetivo reconhecer e conceder direitos aos seus segurados. A renda transferida pela Previdência Social é utilizada para substituir a renda do trabalhador contribuinte, quando ele perde a capacidade de trabalho, seja pela doença, invalidez, idade avançada, morte e desemprego involuntário, ou mesmo a maternidade e a reclusão. (MINISTÉRIO DA PREVIDÊNCIA SOCIAL, 2009a). O benefício da aposentaria hoje previsto na lei do Brasil garante o recebimento de um valor de bonificação pelos anos de contribuição. Tem o direito assegurado trabalhadores pelo critério idade urbanos a partir de 60 anos de idade (mulheres) e acima de 65 anos (homens), rurais com diferença de 05 anos a menos tanto para homens quanto para mulheres. (MINISTÉRIO DA PREVIDÊNCIA SOCIAL, 2009b). O mesmo benefício pode ser adquirido pelo tempo de contribuição, que aponta 35 e 30 anos de contribuição, respectivamente para homens e mulheres. (MINISTÉRIO DA PREVIDÊNCIA SOCIAL, 2009b).

Pesquisas apontam que a aguardada aposentadoria não corresponde à expectativa dos cidadãos atualmente. A espera pela aposentadoria como ideal social e divulgada como fase de descanso e lazer da vida não encontra ligação com a atual realidade brasileira e é vista hoje como complementação salarial, para muitos cidadãos. Consequências de terem-se ainda políticas sociais que dificultam e a equiparação das diferenças individuais e os idosos pertencem a esta fatia. Sendo assim, hoje muitos trabalhadores permanecem trabalhando mesmo após a aposentadoria, por não ser suficiente apenas o valor recebido pelo benefício da previdência e que este direito é assegurado pela legislação brasileira, ou seja, o indivíduo tem o direito de permanecer no mercado de trabalho mesmo após aposentar-se. Não só tem o direito assegurado, como também devem ser tratados como iguais nos processos seletivos de empregos e concursos (BITENCOURT; GALLON; BATISTA, 2011).

Esses idosos, que permanecem no mercado de trabalho, continuam a contribuir com a Previdência social, contudo, o a contribuição dos idosos na produtividade do país não é apenas importante do ponto de vista econômico, mas também e principalmente em relação à qualidade da vida dos mais velhos, destacando o importante significado do trabalho e do sentir-se ativo para o idoso. Neste sentido, a aposentadoria viria a ser não só uma fase de mudança para novos papéis sociais, mas uma nova fase, ainda de desenvolvimento, fase esta que pode representar ainda um terço da vida dos indivíduos com longa expectativa de vida. (LOCATELLI e FONTOURA, 2013).

Contudo, mesmo que tardiamente, o momento da aposentadoria merece atenção, pois conforme já mencionado no texto, possui ligação íntima com o significado do trabalho e da produtividade dos indivíduos. O distanciamento do trabalho acaba conectando-os aos medos, ao receio em relação ao sentimento de inutilidade, improdutividade, diminuição dos laços sociais, baixa condição econômica, que restringe ainda mais as atividades sociais e acelera o processo do envelhecimento social.

Barreto e Ferreira (2011) discorrem sobre a importância desta fase na vida dos sujeitos e destaca a atuação de empresas melhor estruturadas e que já tem visão sobre este período da vida, mas baseadas na 'marca' da ação como sendo de cunho de Responsabilidade Social, trabalham assuntos relacionados ao cuidado com saúde, questões financeiras e novas 
atividades, para que possam pensar em investir seu tempo disponível em atividades prazerosas e que possibilitem os sujeitos a atravessar este momento da chamada aposentadoria que está tão ligado ao incômodo do envelhecimento humano, marco que na grande maioria das vezes está carregado de angústia, pois remete ao fim da existência, a finitude da vida.

Para que o processo do luto se dê de forma 'natural', o sujeito precisaria transferir a sua energia libidinal para outro objeto, superando a perda do anterior. No entanto, como explicitado anteriormente, não se trata de uma tarefa fácil, ainda mais quando há toda uma construção que faz com que o sujeito acredite que a identificação total com o trabalho é algo fundamental. Se esta perda não é superada pelo indivíduo, que acaba por confundi-la com a perda do seu próprio $\mathrm{Eu}$, tem-se o quadro melancólico e todas as suas manifestações (BARRETO e FERREIRA, 2011).

Pode-se destacar aqui, fase importante da vida dos trabalhadores em processo de envelhecimento, em que a política de Gestão de Pessoas, deve atuar (com o desenvolvimento dos PPA'S - Preparação para Aposentadoria), possibilitando uma passagem mais amena e preparando estes indivíduos, para o momento da aposentadoria.

Completando todos os aspectos discutidos acima, Silva (2008), traz uma reflexão muito pertinente em relação ao imaginário cultural da velhice e da terceira idade na modernidade. $\mathrm{O}$ autor nos convida a pensar sobre o engrandecimento das potencialidades e valorização do envelhecimento, no sentido positivo, do bem estar, da produtividade, da saúde, chamando atenção para o direito de escolha e também as limitações dos cidadãos. Menciona que se pode estigmatizar pela via da inutilidade, do descartável, não podemos exigir aos sujeitos, que sejam e continuem no exercício daquilo que não lhe for satisfatório ou possível.

\subsection{A Docência e as Mudanças no Mundo do Trabalho}

A categoria trabalho fundamenta o entendimento da produção da existência humana enquanto atividade e categoria central de compreensão do capitalismo, do complexo mundo do trabalho e da educação, inseridos, hoje, na era globalizada da tecnologia da informação (CIAVATTA, 2005). Sob este aspecto, ressalta Sennet (2006, p. 69) que "o tempo nas instituições e para os indivíduos não foi libertado da jaula de ferro do passado, mas sujeito a novos controles do alto para baixo". Ressalta o autor que a lógica métrica do tempo passou do relógio de ponto para a tela do computador. Considerando que trabalhar em casa é a característica do novo regime, isto faz com que o trabalho se torne fisicamente descentralizado, fazendo com que o tempo da flexibilidade seja o tempo do novo poder.

Segundo Antunes (2008), as principais mudanças sofridas pelo mundo do trabalho foram acentuadas pelo capitalismo contemporâneo, em escala global, tanto na sua estrutura produtiva, quanto no universo de seus ideários e valores. Neste contexto, inserem-se os serviços públicos, tais como a educação, que sofreram um significativo processo de reestruturação, evidenciando-se as formas produtivas flexibilizadas e desregulamentadas, as chamadas acumulação flexível e o toyotismo, em substituição ao padrão taylorista/fordista; bem como o desmonte do modelo de regulação social-democrático que deu sustentação ao chamado estado de bem-estar social, em vários países centrais, através da desregulação neoliberal e privatizante.

Neste contexto observam Lemos e Costa (2012) que:

[...] o discurso sobre a empregabilidade como a forma de imposição da visão sobre a crise do mundo do trabalho conveniente às classes dominantes no campo econômico

Costa, D. V. F.; Moura, R. G.; Nascimento, R. P.; Salvá, M. N. R.; Simão, L. A. S. 
[...] tem a peculiaridade de transferir para os trabalhadores - dominados no campo da produção - os ônus da reestruturação produtiva, na medida em que são eles que devem criar as condições que permitam sua entrada e permanência no mercado. A hipótese do mercado de trabalho ser reformulado, com vistas a prever formas de integração capazes de incorporar os contingentes de trabalhadores que se tornam excedentes, problema central na esfera produtiva, fica em segundo plano, bem como as propostas que pressupõem a ação do Estado como promotor de políticas capazes de incrementar a criação de empregos.

O capitalismo trouxe para o mundo contemporâneo, intensas mudanças tecnológicas, com impactos consideráveis para as relações do indivíduo e da sociedade, principalmente no que tange aos sentidos do trabalho, à educação, à economia, bem como às demais esferas sociais. No âmbito destas políticas, as reformas educacionais promovidas pelos organismos internacionais aos países da América Latina, nas duas últimas décadas do século XX e em curso no novo milênio, propiciaram mudanças consideráveis nas formas de organização e gestão das instituições de ensino superior, impactando, sobretudo, o trabalho docente.

Ao final do século XX, evidenciou-se a ruptura da promessa da escola como entidade integradora, de formação para o emprego, para a "[...] revalorização do papel econômico da educação, da proliferação de discursos que começaram a enfatizar a importância produtiva dos conhecimentos", dentro do contexto de competição econômica, na era da globalização (GENTILI, 2005, p. 49).

Nos países periféricos como o Brasil, a reforma do Estado e as muitas políticas educacionais e ajustes estruturais impostas pelos últimos governos (face superestrutural da reestruturação produtiva) ditaram, sob a égide dos organismos internacionais do capital, os objetivos e o formato das mudanças nas universidades brasileiras na última década para que se ajustem ao processo de reestruturação do trabalho docente (MAUÉS e MOTA, 2011; FERREIRA, NASCIMENTO e SALVÁ, 2014). Como marco inicial da implantação das políticas públicas nacionais em educação, foi aprovada a Lei de Diretrizes e Bases para a Educação Nacional (LDB), em 20 de dezembro de 1996, entre outras iniciativas estatais, tais como: a reforma da educação tecnológica e do aparato de formação profissional; a execução de mecanismos legais e financeiros viabilizadores da privatização, da fragmentação e do empresariamento da educação superior; as alterações na formação de professores para os diferentes níveis de modalidade de ensino; a definição de novos parâmetros e diretrizes curriculares nacionais e seus instrumentos de avaliação (NEVES, 2006).

Observam Zonatto et al. (2013) que "a universidade é o local no qual se produz e dissemina o conhecimento", considerando que a aquisição de mais conhecimento e habilidades aumenta o valor do capital humano das pessoas. Sobre o legado dos docentes de produzir e divulgar conhecimento, ressalta Alcadipani (2011, p. 348), "o professor precisa ter a tranquilidade de que quando ele atingir certo nível de desenvolvimento intelectual e senioridade em uma dada área, ele não será descartado por não fazer pontinhos". A academia precisa levar em consideração as suas peculiaridades e sua finalidade social.

\section{Procedimentos Metodológicos}

Esta é uma pesquisa de natureza qualitativa, com a finalidade de compreender o sentido do trabalho para o professor idoso de ensino superior.A escolha do método baseou-se em Gaskell (2008, p. 65), a fim de contribuir para o conhecimento de dados básicos que permitem o desenvolvimento, a compreensão da situação local e a relação estabelecida entre

\footnotetext{
“Trabalhar É Manter-Se Vivo”: Envelhecimento e Sentido do Trabalho para Docentes do Ensino Superior
} 
os atores sociais, com o objetivo de compreender "as crenças, atitudes, valores e motivações" sobre o comportamento dos indivíduos em determinados contextos sociais.

A escolha do método de análise do conteúdo deve-se ao fato dos estudos se basearem em procedimentos sistemáticos e objetivos de descrição do conteúdo das mensagens, com apuração das "descrições de conteúdo mais aproximativas, subjetivas, para pôr em evidência com objetividade a natureza e as forças relativas dos estímulos a que o sujeito é submetido" (BARDIN, 1977, p. 31).Para a coleta dos dados, utilizou-se a entrevista longa, (McCRAKEN, 1988), que justifica a escolha do método por se tratar de um tipo de entrevista em profundidade. Os dados foram coletados por meio de pesquisa de campo, em duas instituições de ensino superior públicas, e em duas instituições de ensino superior privadas, por meio de roteiro semiestruturado de entrevista, composto por 18 tópicos guia. O roteiro foi previamente testado, através da realização de entrevistas piloto. As entrevistas duraram cerca de 50 a 90 minutos. As entrevistas foram gravadas e posteriormente transcritas, assegurandose a confidencialidade e sigilo dos entrevistados convidados.

De acordo com Bauer e Aarts (2002), em pesquisa qualitativa não se pode estimar um tamanho ideal de corpus. No entanto, foram realizadas dezesseis entrevistas, o que possibilitou a identificação, conforme sugere Gaskell (2002), da apresentação das semelhanças e não fornecimento de mais subsídios necessários à compreensão do fenômeno.

O quadro ou corpus de entrevistados foi composto por dezesseis docentes, sendo doze homens e quatro mulheres, residentes na cidade do Rio de Janeiro e Juiz de Fora, com idades entre 64 e 78 anos. As entrevistas foram realizadas no período de março a junho de 2015.

Conforme menciona Kelle (2003), a partir da década de 1980 intensificou-se o uso de pacotes de softwares para tratamento dos dados compilados pela pesquisa qualitativa. Desta forma, com o intuito de facilitar a análise, foi utilizado o programa ATLAS TI para tratamento dos dados compilados pela pesquisa.Com uma revisão da literatura, (MCCRAKEN, 1988; LOFLAND, 2006), estabeleceram-se as oito categorias a priori, as quais auxiliaram na construção do roteiro semiestruturado de entrevistas. Através da análise das entrevistas, foi possível identificar mais 90 fatores que não foram inicialmente esperados e classificados como categorias emergentes.

\section{Apresentação e Análise dos Dados}

A presente seção tem a finalidade de apresentar os resultados da pesquisa realizada, a partir dos procedimentos metodológicos já descritos, de acordo com as categorias definidas a priori e as emergentes mais relevantes, trabalhadas no estudo.

\subsection{A Centralidade do Trabalho}

Nesta categoria buscou-se identificar as mudanças ocorridas no trabalho do professor com 60 anos ou mais e os reflexos destas transformações na representação social destesujeito no mundo contemporâneo.

Evidenciou-se, nas entrevistas, a maximização da concorrência e da competitividade no mercado de trabalho, conforme citado por Standing (2013).

A dificuldade de se permanecer ativo até hoje é o mercado de trabalho. Para você se tornar empregado de alguma empresa, a idade é um obstáculo [...] a tendência é rejeitar as pessoas que têm mais de 60 anos (E1). 
Pensando no mercado de trabalho é aquilo que falei há pouco, ainda me enxergo tolhido, discriminado, a idade discrimina o indivíduo (E3).

As significativas mudanças ocorridas no campo da tecnologia foi um dos fatores, observados pelos entrevistados, que trouxeram impactos consideráveis para o trabalho docente, acentuando-se as transformações dos processos que o mundo do trabalho vem sofrendo no âmbito da produção, como observado por Harvey (1989).

O mundo mudou substancialmente. Teve a introdução da tecnologia, de computadores e muitos valores que eram negativos passaram a ser positivos e muitos valores positivos passaram a ser negativos. Eu acho que sou o único que usa gravata, não é? [...] Na minha época, a mulher era preparada pra criar filho, cuidar de criança, da casa. Hoje, o homem divide a despesa com a mulher. Cada um tinha sua tarefa definida, hoje não tem mais (E6).

O exercício pleno de meu trabalho, com as diversas interfaces tais como gestão, produção, coordenação de projetos compromete relativamente meu lazer, pois o trabalho em si, hoje, especialmente com acesso à internet em todos os lugares, torna impossível se afastar, mesmo durante as férias, das tarefas diárias. Isso é feito nos horários em que não se está na instituição [...] (E5).

A iminência do fim do trabalho mencionada por Dejours (2012), devido à celebração de um poder imaginário social contemporâneo, pode ser verificada na fala dos entrevistados, quando observa-se que a integração produtiva se alimenta do consumo flexível de competências diferenciadas, não constatando-se o fim do trabalho como medida de valor, mas uma mudança qualitativa da dimensão do trabalho multifuncional (ANTUNES, 2008; KUENZER, 2008).

Eu uso minhas férias e meus finais de semana. Minha condição acadêmica exige que eu exerça atividades que são docentes e administrativas. Eu passo a semana toda interagindo em aulas presenciais e à distância (E9).

Nas entrevistas, observou-se que o processo de racionalização econômica proposta pela informatização, citada por Gorz (2007), chegou às universidades. Desta forma, no próximo item, será analisado o sentido do trabalho para o professor idoso, concernente ao seu processo de transformação individual, intelectual e sua interação com a sociedade.

\subsection{O Sentido do Trabalho para o Professor Idoso}

Nessa categoria investigou-se como é a visão do professor com mais de 60 anos de idade que se mantém atuante na sua relação com o trabalho. Mesmo com a diversidade de relatos, pôde-se observar que os entrevistados mostraram, unanimemente, ter uma ótima relação com o trabalho. Ficou evidente a importância da questão financeira na decisão de se manterem produtivos, mas destacaram, ainda, a realização no desempenho da função, a inclusão social e a existência de uma rotina a seguir como pontos bem marcados pelosentrevistados. Os pontos citados revelam as idéias de Antunes (2009) e Bendassoli 
(2009) onde os autores colocam que os sentidos do trabalho são amplos e que uma vida tem sentido quando existe sentido na atividade de trabalho que se realiza.

\begin{abstract}
A vantagem de se permanecer ativo é que eu estou no mundo. Eu estou participando e isso traz força interior. Ano que vem faço oitenta anos. Então eu ia ficar em casa olhando pro teto? E também não quero fazer outra coisa. Quero isso! (E1)
\end{abstract}

Permanecer na ativa tem dois motivos: o primeiro é de manter o status de vida financeiramente [...] o outro é a importância da pessoa continuar trabalhando, continuar vivendo, sentido prazer na vida [...] (E3)

É importante observar que os entrevistados ressaltam o prazer em trabalhar, em ser útil, em ter um compromisso de vida, corroborando com Carvalho (2009), porém destacam a satisfação na atuação da carreira docente. Os sujeitos enfatizam que ser professor contribui na gratificação do trabalho.

Você acaba ambientando-se nesse mundo jovem e, às vezes, nem percebe que a idade atingiu você. (E10)

Eu adoro. Cada vez que eu saio de uma sala de aula, aos sessenta e quatro anos, eu me sinto realizado. Sinto-me com dezoito anos quando comecei a dar aula de inglês. ... hoje para mim é gratificante dar aula, não faço isso para ganhar dinheiro, faço pelo prazer de dar aula, daria até aula de graça. Ah é bom, me distrai, eles (os alunos) me rejuvenescem.

...eu recomendo todo mundo a trabalhar e trabalhar até tarde, para se manter jovem, se manter, digamos, se manter com saúde e manter um espírito assim, um foguinho de desejo. (E12)

Apesar das pesquisas atuais apontarem que grande parte dos idosos tem hoje capacidade de trabalhar (Coutrim, 2006), percebeu-se, na presente pesquisa, que mesmo sendo o trabalho considerado uma atividade prazerosa por parte dos docentes entrevistados, observou-se que estes mesmos sujeitos identificam o preconceito no exercício de seu trabalho, por conta da idade, tema a ser abordado no próximo item.

\title{
4.3 Preconceito do Idoso no Trabalho
}

Essa categoria emergiu durante a análise dos dados e mereceu destaque no presente trabalho por se verificar que, em muitas falas dos professores idosos entrevistados, sem mesmo serem questionados diretamente sobre o tema, foram surgindo evidências sobre o preconceito em relação à idade, reflexo das significativas mudanças ocorridas nas relações do indivíduo e da sociedade, promovidas pelas transformações verificadas no campo da tecnologia, da economia da cultura e do trabalho, como salienta Harvey (1989). Os sujeitos abordavam esse tema ao serem questionados sobre outros pontos do roteiro de entrevista, deixando explícito o desejo de abordarem esse assunto na pesquisa.

O velho ele está sempre superado... porque ele é velho. Então a visão dos novos é que o velho não tem agilidade em termos de conhecimento, em termos de raciocínio

Costa, D. V. F.; Moura, R. G.; Nascimento, R. P.; Salvá, M. N. R.; Simão, L. A. S. 
para muitos temas e que ele tem outra visão do mesmo problema, uma visão diferente da dele. (E14)

Pensando no mercado de trabalho é aquilo que falei: ainda me enxergo tolhido, discriminado. A idade discrimina o indivíduo. (E6)

Ao comentar sobre investimentos que as empresas fazem em treinamentos, o E15 opina que

...nas pessoas mais jovens sim... e isso não é de hoje, por muito tempo, quando eu trabalhava na parte administrativa, já sentia isso que a tendência era isso, preparar os mais novos para chegar à experiência dos mais antigos, então qualquer treinamento e qualquer melhoria a tendência era levar os mais jovens e não os velhos.

$\mathrm{Na}$ fala sobre o relacionamento com os alunos o E16 evidencia:

... mas percebo que entre aluno e professor idoso tem sim, dificuldade. Não tem medição, é uma percepção... mas acho que é um pouco do jovem ter preconceito.

Acreditava-se que, com as debilidades decorrentes do avanço da idade, o idoso não seria capaz de continuar a exercer suas atividades no trabalho, julgando-os incapazes e marginalizando-os. Porém, com o crescente número de idosos na população, esse fato vem mudando consideravelmente, como relata Fontoura (2012). No entanto, ainda faltam políticas institucionais de incentivo à permanência do professor idoso no mercado de trabalho, como verificado na fala de alguns entrevistados.

\footnotetext{
Eu acho que a política de incentivo institucional para que o professor idoso dê continuidade ao desenvolvimento do seu trabalho é muito pouca. Eu acho que o que há é o que todo mundo recebe, o tal do abono permanência [...] E muita gente fica por causa disso. Eu não considero isso um estímulo. Eu acho que uma política realmente de estímulo, para que os mais velhos, que tenham experiência acumulada e que podem enriquecer a Instituição são muito pouco valorizados. Eu diria até que são deixados para escanteio. Não há, hoje, na instituição, uma decisão de se estimular o conhecimento acumulado dos mais velhos. Pelo contrário, há uma política de que se afastem cada vez mais. (E4)
}

Neste item, observa-se a lógica da obsolescência citada por Gaulejac (2007), que arrasta o indivíduo em busca de sentido e de reconhecimento jamais satisfeita, gerando uma competição, através de um sentimento de assédio generalizado, com a cultura do alto desempenho se impondo como modelo de eficiência. Tais circunstâncias propiciam o esgotamento profissional, o estresse, enquanto que o sofrimento no trabalho se banaliza.

\subsection{Consequências do Envelhecimento no Trabalho}

$\mathrm{Na}$ continuidade da análise dos dados surgiu outra categoria emergente que merece ser evidenciada por corresponder ao tema proposto. Muitos entrevistados relataram consequências do envelhecimento e suas implicações no trabalho docente, destacaram, por exemplo, a dificuldade em utilizar novas tecnologias. 
As novas ferramentas de trabalho utilizadas hoje, muitas delas, nós temos dificuldade de absorver, nós não temos disposição para absorvê-las, porque elas são tecnologias que envolvem uma entrega muito grande para nós e para todos... (E2)

Além da dificuldade em lidar com o surgimento de novas tecnologias no trabalho, percebeu-se também considerações em relação às condições físicase à saúde que afetam na execução do trabalho.

... Claro que há um componente no limite não é? Que a idade impõe de energia física, da energia física. Ela vai caindo não é? (E8)

Com os anos não é? É... Mas na medida do possível, você tentar manter ter uma vida saudável e manter essa energia e ter essa satisfação, não é? Do exercício da docência, eu acho que isso é fantástico. (E7)

Assim, percebe-se por meio das analises, que embora os docentes idosos continuem ativos no mundo do trabalho mesmo depois da aposentadoria, reconhecem que o envelhecimento traz implicações que dificultam a execução de suas funções, tais como o avanço tecnológico e a "fragilização" da saúde pelo envelhecimento.

\subsection{Trabalho e Gênero}

Neste tema, buscou-se investigar se existemdiferenças nas relações dentro do ambiente profissional, provocadas pelo gênero dos docentes idosos. Nas respostas aos questionamentosacerca dessa categoria, pôde-se perceber a existência de um preconceito não declarado por parte dos homens frente ao trabalho docente feminino. Ou seja, quando questionados sobre a existência ou não de uma diferença para o exercício da função, todos afirmaram que não há, porém nas próprias explicações pôde-se perceber uma diferenciação, com destaque para a visão da resistência física do homem maior em relação à da mulher.

Olha, é, alguma coisa assim que poderia ser diferente, talvez fosse a resistência física né, porque obviamente que você, é tendo que dar aula principalmente em pé né, e falando o tempo todo e falando geralmente com o tom de voz mais elevado, as turmas hoje são grandes né, nós temos turmas de 70, 60, 70, 80 alunos até 90 alunos, então diria que nesse ponto o homem tem um pouco mais de resistência física do que a mulher né, condições fisiológicas mesmo. (E11)

Embora se tenha levantado a questão física como diferença no trabalho docente, também notou-se uma desvalorização do trabalho feminino:

Não... não há discriminação... para determinadas atividades ainda hoje parece ser atividades que foram desenvolvidas ao longo do tempo apenas por homens... do tipo engenharia... então atividades que sempre foram cursos que até 10, 20 anos atrás era quase que apenas os rapazes cursavam engenharia. Mas hoje as mulheres tem o mesmo desempenho. (E4) 
Já para as mulheres entrevistadas, todas evidenciaram que sentem essa diferenciação por serem mulheres.

O Homem, normalmente, quando você tem, por exemplo, uma reunião... normalmente, os coordenadores da reunião, sendo homens, eles querem ouvir a opinião do homem sempre antes. É uma coisa que venho notando há algum tempo. Não só aqui, mas em outros locais também. Acabei de participar de uma reunião. Só tinha eu e mais uma mulher. No Ministério, lá em Brasília. E eu notei isso, mais uma vez. Existe sim. Existe um privilégio para o sexo masculino. Isso é muito evidente. $\mathrm{Na}$ área científica também. (E3)

As dificuldades são muitas. Primeiro porque no serviço público existe uma filosofia de que todos são iguais. E isso não é verdade. Isso é uma falsa afirmativa. A maiorias das chefiasestão com os homens. Então existe, realmente, até mesmo não intencional, talvez, mas de aglutinar o maior número de pessoas do mesmo sexo. Isso é cultural em nosso país. (E3)

$\mathrm{Na}$ fala dos entrevistados percebe-se que a docência superior, em sua natureza era, no passado, de exclusividade masculina eanalisando as entrevistas pôde-se perceber que hoje ainda existem problemas de gênero no mundo do trabalho. Na análise dos dados notouseainda que no discurso dos docentes homens há uma visão de inexistência de preconceito com relação às mulheres. Todavia, na visão das docentes mulheres entrevistadas, em relação à sua atuação profissional, há relatos que buscam evidenciar a existência de diferenças de tratamento entre os gêneros, destacando certa falta de credibilidade, pelos homens, em relação ao gênero feminino, contrariando a visão exposta pelos docentes homens.

\subsection{Representação da Aposentadoria}

Nesta categoria, buscou-se compreender a percepção dos entrevistados em relação à aposentadoria e o que ela lhes representa. Esta foi uma categoria difícil de ser abordada, pois se trata de um assunto delicado de ser investigado, talvez por haver ainda receio dos entrevistados quanto ao tema. Considerando-se que os sujeitos de pesquisa são pessoas ativas na profissão docente, a sensação foi de que o termo "idoso", "envelhecimento" e "aposentadoria" estavam muito distantes da realidade em que se encontravam.

A importância do trabalho, enquanto fator estruturante do ser social evidenciou-se na fala dos entrevistados, mas a flexibilidade do mercado de trabalho, promovida pelo cenário neoliberal, significa uma agenda de riscos para esses trabalhadores e seus familiares, tal como aborda Standing (2013). Neste contexto, insere-se a aposentadoria. Os entrevistados evidenciaram que o fator financeirotem grande importância na decisão de se manterem trabalhando. Destacaram que se manterem ativos contribui na manutenção dos laços sociais e na sensação de serem produtivos e úteisà sociedade e à família.

Se eu me aposentar hoje eu perco dinheiro. É uma razão... Não é única, mas sim é uma das razões. (E3) 
... ah não, muito ruim. Eu acredito que aposentar em outras atividades tudo bem, mas aqui no magistério, sei não, para mim vai ser horrível o dia que eu parar de dar aula. É muito ruim ficar velho minha filha, não queira ficar velho não... muito ruim. (E13)

\footnotetext{
Quando às vezes penso em me aposentar, pergunto a alguns colegas que já se aposentaram e eles dizem que estar aposentado, sem ter uma atividade formal, uma atividade que os levassem a ter um compromisso profissional, era algo muito desgastante, e poderia até se dizer, até estressante... e leva a uma tristeza muito grande de estar apenas se pensando no passado, das coisas boas que se viveu. Tenho um receio sobre isso... (E14)
}

Dos 16 entrevistados, nenhum apresentou uma relação positiva com a aposentadoria. A importância do trabalho como meio social, conforme destacado por Carvalho (2004), apresenta algumas dimensões em que a atividade laboral se faz presente. O autor comenta, conforme exposto no referencial teórico e pôde ser observado nas entrevistas, que o trabalho possibilita, além de comparecerem financeiramente no orçamento familiar, a autonomia, o funcionamento das atividades mentais e a participação como atores sociais.

A fase da aposentadoria, como mencionado por Barreto (2011), é um momento da vida do trabalhador com profundas mudanças e adaptações e, por estar intimamente ligado ao significado do trabalho e da produtividade dos indivíduos, merece atenção e preparação. Conforme acrescenta Locatelli (2012), trata-se de uma nova fase do desenvolvimento, ainda não conhecida pelos indivíduos e que, nitidamente, aparece nas entrevistas com um momento de receio por parte dos trabalhadores que se encontram perto do momento da aposentadoria.

\section{Considerações Finais}

Neste estudo observou-se que o sentido do trabalho para o professor idoso tem dimensões significativas, refletindodiretamente no seu bem estar físico, mental e emocional, tendo em vista esta condição permitir que se mantenha produtivo perante a família e à sociedade, a possibilidade de plena realização profissional, de inclusão social e, ainda, prover sua liberdade de autonomia.

Destaca-se, no presente artigo, a existência do preconceito em relação à idade do professor com 60 anos ou mais. Verificou-se que as debilidades decorrentes do avanço da idade, que por vezes o torna marginalizado, não o impede de continuar a exercer suas atividades no trabalho. Tal fato pode ser verificado na manutenção docrescimento da população idosa no efetivo dos trabalhadores, correspondendo à inclusão da economia brasileira às mudanças que ocorreram na base produtiva do capitalismo, em escala global. No entanto, ainda faltam políticas institucionais de incentivo à permanência do professor idoso no mercado de trabalho. As conseqüências do envelhecimento e suas implicações no trabalho docente proporcionam sensações desofrimento, gerando a banalização da competitividade e da sensação de obsolescência devido ao conflito entre as diferentes gerações, ao avanço tecnológico e ao desenvolvimento de novos conhecimentos.

No mundo do trabalho, as diferenças relacionadasao gênero dos professores idosos consistiram no preconceito velado por parte dos docentes do sexo masculino, com relação ao exercício da função, em face do trabalho dos docentes do sexo feminino, tendo em vista à comparação apresentada a maior resistência física do homem com relação à da mulher. Embora se tenha levantado a questão física como diferença no trabalho docente, também se notou uma desvalorização do trabalho feminino, levando-se em conta o desempenho Costa, D. V. F.; Moura, R. G.; Nascimento, R. P.; Salvá, M. N. R.; Simão, L. A. S. 
necessário para o exercício em determinadas áreas e atividades. Além disso, na visão das mulheres docentes, verificou-se que existe um privilégio na área científica para o sexo masculino, remetendo-se à discussão à cultura política e cultural do país, na atualidade.

De outra forma, a aposentadoria apresentou-se como uma ameaça às garantias adquiridas pelo professor idoso, quando em atividade, pois as mudanças e adaptações, decorrentes da aposentadoria, conecta-o ao sentimento de inutilidade, de improdutividade, de diminuição dos laços sociais e de baixa condição econômica, por tratar-se de um mundo ainda desconhecido e estar intimamente ligado ao significado do trabalho vivenciado por ele no exercício de suas atividades. Verificou-se que as mudanças ocorridas no trabalho do professor idoso são reflexos do consumo flexível de competências diferenciadas, fruto do capitalismo, e promotoras da maximização da concorrência e da competitividade da classe no mercado de trabalho, promotora do processo de reestruturação individual e nas relações do indivíduo com a sociedade.

\section{Referências}

ALCADIPANI, R.Academia e a fábrica de sardinhas. Revista Organização e Sociedade, N. 57, Vol. 18, Abr./Jun., Salvador, 2011.

ANTUNES, R. Adeus ao Trabalho? Ensaio sobre as Metamorfoses e a Centralidade do Mundo do Trabalho. São Paulo: Cortez, 2008.

.O caracol e sua Concha: Ensaios sobre a nova Morfologia do trabalho. São Paulo: Bomtempo, 2008.

Os sentidos do trabalho: ensaio sobre a afirmação e a negação do trabalho. São Paulo: Bomtempo, 2009.

ARAÚJO, R. R.; SACHUK, M. I. Os sentidos do trabalho e suas implicações na formação dos indivíduos inseridos nas organizações contemporâneas. In: Revista de Gestão USP, São Paulo, v. 14, n. 1, p. 53-66, janeiro/março. 2007.

BARRETO, R. O.; FERREIRA, L. Luto e melancolia: Contribuições psicanalíticas para o entendimento dos reflexos da aposentadoria na subjetividade dos indivíduos. Anais.... Encontro ANPAD, Rio de Janeiro, RJ, Brasil, 35, setembro. 2011.

BAUER, M. W.;AARTS, B..A construção do corpus: um princípio para a coleta de dados qualitativos. In: BAUER, M. W., \& GASKELL, G. Pesquisa qualitativa com texto, imagem e som: um manual prático. Petrópolis: Vozes, 2002.

BAUMAN, Z. Amor Líquido: Sobre a Fragilidade dos Laços Humanos. Rio de Janeiro: Jorge Zahar, 2004.

BENDASSOLLI, P. F. Psicologia e trabalho: apropriações e significados. São Paulo: Cengage Learning, 2009.

Trabalho e identidade em tempos sombrios: insegurança ontológica na experiência atual com o trabalho. São Paulo: Idéias \& Letras, 2007.

BITENCOURT, B. M., GALLON, S.; BATISTA, M. K. Para além do tempo de emprego: o sentido do trabalho no processo de aposentadoria. Revista de Ciências da Administração, v. 13, n. 31, 30-57, 2011. 
BRAGA, S. F. M., MAESTRO FILHO, A., SILVEIRA, R.B.; GUIMARÃES, L.V.M. As políticas públicas para os idosos no Brasil: A cidadania no envelhecimento. Anais.... Encontro de Administração Pública e Governança da ANPAD, Salvador, BA, Brasil, 2, 2008.

BRASIL, MINISTÉRIO DA PREVIDÊNCIA SOCIAL (2009a). Aposentadoria por tempo de brasileiros: muito além dos 60? Caderno Temático 6, 77-87, (pp. 453-480), Rio de Janeiro: Ipea, 2009.

BRASIL, MINISTÉRIO DA PREVIDÊNCIA SOCIAL (2009b). Aposentadoria por idade. Recuperado de: <http://agencia.previdencia.gov.br/e-aps/servico/341.

CAMARANO, A. A. O idoso brasileiro no mercado de trabalho. Texto para discussão n. 830. Rio de Janeiro: IPEA, 2001.

CARMO, P. S. A ideologia do trabalho. São Paulo: Moderna, 1992.

CARVALHO, A. S.Gestão de pessoas e envelhecimento: sentido do trabalho para o idoso. Anais...Encontro da ANPAD. São Paulo, SP, Brasil, 33, 2009.

CIAVATTA, M. Mediações do mundo do trabalho: a fotografia como fonte histórica. In: LOMBARDI, J. C., SAVIANI, D., \& SANFELICE, J. L. (Orgs.). Capitalismo, trabalho e educação. Autores Associados: São Paulo, 2005.

COUTRIM, R. M. E. Idosos trabalhadores: perdas e ganhos nas relações Inter geracionais. Revista Sociedade e Estado. maio/ago; 21(2), 367-90, 2006.

DEBERT, G. G. A. Invenção da terceira idade e a rearticulação de formas de consumo e demandas políticas. Revista Brasileira de Ciências Sociais (RBCS). No. 34, jan, 1997.

DEJOURS, C. Trabalho Vivo, Trabalho e Emancipação. Brasília: Paralelo 15, 2012.

DOURADO, D. P. et al. Sobre o sentido do trabalho fora do enclave de mercado. In:Cadernos Ebape, v. 7, no 2, artigo 10, Rio de Janeiro, Jun. 2009.

ENGEL, C. L., C. P.R.A.Considerações sobre o envelhecimento no Brasil. Anais....Encontro Anual da Associação Nacional de Pós-Graduação em Ciências Sociais - ANPOCS. Caxambu, MG, Brasil, 36, 2012.

FERREIRA, P. C. A. S.; NASCIMENTO, R. P.; SALVÁ, M. N. R. Professor: Profissão de Risco. Uma análise do impacto da gestão de IES provadas sobre o trabalho docente. Revista Sociedade, Contabilidade e Gestão, v. 9, n. 2, Rio de Janeiro, 2014.

FONTOURA, D. S.; PICCININI, V.C. Envelhecimento populacional e gestão de pessoas: pesquisas internacionais e notas para o Brasil. Anais....Encontro da ANPAD. Rio de Janeiro, RJ, Brasil, 36, 2012.

GASKELL, G. Entrevistas individuais e grupais. In: M. W. Bauer \& G. Gaskell, G. (Org.), Pesquisa qualitativa com texto, imagem e som: um manual prático. (P. A. Guareschi, Trad.). Petrópolis: Vozes, 2002.

GAUlEJAC, V. Gestão como Doença Social: Ideologia, Poder Gerencialista e Fragmentação Social. São Paulo: Ideias e Letras, 2007.

GENTILI, P. Três teses sobre a relação trabalho e educação em tempos neoliberais. In: LOMBARDI, J. C., SAVIANI, D., \& SANFELICE, J. L. (Orgs.). Capitalismo, trabalho e educação. São Paulo: Autores Associados, 2005.

GIAQUETO, A.; SOARES, N.O trabalho e o trabalhador idoso. Seminário de Saúde do Trabalhador e Seminário "O Trabalho em Debate: Saúde Mental Relacionada ao Trabalho". Franca, SP, Brasil, 7 e 5, 2010.

Costa, D. V. F.; Moura, R. G.; Nascimento, R. P.; Salvá, M. N. R.; Simão, L. A. S. 
GORZ, A. Metamorfoses do trabalho: crítica da razão econômica. São Paulo: Annablume, 2003.

HARVEY, D. Condição Pós-Moderna. São Paulo: Edições Loyola, 1989.

KELLE, U. (2003). Análise com auxílio de computador: codificação e indexação. In: KUENZER, A. Z. Reforma da Educação Profissional ou Ajuste ao Regime de Acumulação Flexível? Rev. Trabalho e Educação em Saúde, N. 3, Vol. 5, pp. 491-508, Rio de Janeiro, 2008.

LEMOS, A. H. C., COSTA, A. M. da. A dimensão simbólica da empregabilidade: mercado, políticas públicas e organização social do trabalho. Revista Sociedade, Contabilidade e Gestão, v. 7, n. 2, Rio de Janeiro, 2012.

LIMA, M. P. et al. O sentido do trabalho para pessoas com deficiência. In: Rev. Adm. Mackenzie (RAM), v. 14, n. 2, SÃO PAULO, SP, mar/abr. 2013.

LOCATELLI, P. A. P. C.; FONTOURA, D.S.Envelhecimento populacional e os estudos em administração. Revista Eletrônica Gestão e Sociedade, UFRGS,maio/agosto, 2013.

LOFLAND, J. D. S.; ANDERSON, L.; LOFLAND, L. H. Analyzing social settings. A guide to qualitative observation and analysis.Belmont, CA: Wadsworth Thomson, 2006.

MAUÉS, O. C.; MOTA JR., W. P. A Nova Regulação Educacional e o Trabalho Docente na Pós-Graduação Brasileira. Rev. Linhas Críticas, v. 17, n. 33, p. 385-402, maio/ago., Brasília, DF, 2011.

McCRACKEN, G. The long interview. Ontario: Sage, 1988.

NEVES, L. M. W.A Reforma da Educação Superior e a Formação de um Novo Intelectual Urbano. In: NEVES, L. M. W.; SIQUEIRA, A. C. (Orgs.). Educação Superior: Uma Reforma em Processo. São Paulo: Xamã, 2006.

OLIVEIRA, R.C.S; SCORTEGAGNA, P.A. Políticas Públicas, Educação e Cidadania na Terceira Idade. In: IX Congresso Nacional de Educação - EDUCERE. III Encontro Sul Brasileiro de Psicopedagogia. Paraná, 2009.

PAGÈS, M.et al. O poder das organizações. São Paulo: Atlas, 2006.

POLETTINI, M. R. N. (2010).Idoso: proteção e discriminação no trabalho. Recuperado de:

http://www.conpedi.org.br/manaus/arquivos/anais/bh/marcia_regina_negrisoli_fernandez_pol ettini.pdf>

SENNETT, R.A corrosão do caráter. Rio de Janeiro: Record, 2006.

SIKOTA, C. S.; BRETAS, A.C.P. O significado de envelhecimento para o vendedor ambulante Idoso. Revista de Enfermagem, UFSM, Jan/Abr;2(1), 135-144, 2012.

SILVA, L. R. F. Da velhice à terceira idade: o percurso histórico das identidades atreladas ao processo de envelhecimento. Revista História, Ciências, Saúde - Manguinhos, 15,N.1, Rio de Janeiro, 2008.

SOUZA, R. F.; MATIAS, H. A.; BRÊTAS, A. C. P.Reflexões sobre envelhecimento e trabalho. Revista Ciência Saúde Coletiva, (6), 2835-43, 2010.

STANDING, G. O Precariado: A Nova Classe Perigosa. São Paulo: Autêntica, 2013. 
VIANA, E.; MACHADO, M. Sentido do trabalho no discurso dos trabalhadores de uma ONG em Belo Horizonte. In: Congresso UNA de Psicologia, I, 2009, Belo Horizonte. Anais.... Belo Horizonte: UNA, 2009.

VYGOTSKY, L. S. Obras Escogidas II: Problemas de Psicologia Geral. Madrid: Visor Distribuiciones, 1991.

XIMENES, M. A; CONCONE, M. H. V. B. Velhice e trabalho, uma relaçãopossível?Rev. Kairós.Caderno Temático, 6. 2009;77-87.

WAJNMAN, S.; OLIVEIRA, A. M. H. C. de;OLIVEIRA, E. L. de.Os idosos no mercado de trabalho: tendências e consequências. In: CAMARANO, A. A. (Org.). Os novos idosos brasileiros muito além dos 60 (pp. 453-480). Rio de Janeiro: IPEA, 2004.

WEBER, M. A ética protestante e o espírito do capitalismo. São Paulo: Matin Claret, 2002. ZONATTO, V. C. S.; DALlABONA, L. F.; MOURA, G. D. de; DOMINGUES, M. J. C. S.; RAUSCH, R. B. Evidências da relação entre qualificação docente e desempenho acadêmico: uma análise à luz da Teoria do Capital Humano. Revista Sociedade, Contabilidade e Gestão, v. 8, n. 1, Rio de Janeiro, 2013. 